\title{
MAX WEBER E O “RACISMO CIENTÍFICO” DA SOCIOLOGIA MODERNA
}

Jessé Souza*

Resumo: O texto pretende desmascarar o caráter legitimador a que as "ciências da ordem" - ou seja, comprometidas não com a busca da verdade mas com a reprodução dos interesses que estão ganhando - se prestam a interesses fáticos de dominação fazendo uso do "prestígio científico". A ideia do texto foi usar Max Weber, talvez o autor mais influente das ciências sociais, e demonstrar como sua obra foi utilizada no Brasil e na reflexão da teoria da modernização para a propagação de preconceitos sociais travestidos de conceitos científicos. Como a maior parte da produção contemporânea é ainda influenciada decisivamente pelos pressupostos culturalistas da teoria da modernização - ainda que isso não seja percebido - a tese pretende valer como uma crítica à prática pseudo-científica contemporânea da forma dominante do conteúdo pseudo-científico dentro e fora do Brasil.

Palavras-chave: Racismo científico; ciências da ordem; Max Weber.

\begin{abstract}
This paper aims to uncover the legitimizing character of the 'sciences of order' - those not committed to the truth but to the reproduction of currently prevailing interests - which are submitted to factual interests of domination through the usage of 'scientific prestige'. The idea was to use the writes of Max Weber, perhaps the most influential author in the scope of Social Sciences, and to demonstrate how his work has been employed in Brazil and within modernization theory for the spreading of social prejudices hidden behind (scientific) concepts. Since most of contemporary production is still decisively (and maybe undetected) influenced by culturalist assumptions of the theory of modernization, the thesis intend to be a critique to the contemporary pseudo-scientific practice of the dominant form of pseudo-scientific issues in Brazil and elsewhere.
\end{abstract}

Keywords: Scientific racism; sciences of order; Max Weber.

Para além de toda a importância de Max Weber como um dos pais fundadores da sociologia e também como um dos maiores

* Livre docente em Sociologia. Professor titular de Ciência Política na Universidade Federal Fluminense (UFF) - Niterói, Rio de Janeiro, Brasil. E-mail: souza.jesse@uol.com.br. 
influenciadores do pensamento crítico do século $X X$, sua obra também foi utilizada para a prática do que poderíamos chamar de "violência epistemológica", ou seja, a distorção sistemática da realidade para fins de poder prático, em nome da ciência. Afinal, a ciência herda o prestígio da religião no contexto pré-moderno e assume, em boa parte pelo menos, o papel de explicar o mundo moderno. Não existe tema que seja discutido na esfera pública de qualquer sociedade moderna que não invoque a "palavra do especialista" que fala pela ciência. Assim, o potencial da ciência de produzir efetivo aprendizado individual e coletivo está ligado e muitas vezes decisivamente condicionado, por força de seu prestígio público, a servir de instância legitimadora e primeira e decisiva trincheira da luta social e política pela definição legítima de "boa vida" e "sociedade justa". Em outras palavras: não existe ordem social moderna sem uma legitimação pretensamente científica desta mesma ordem.

Talvez o uso de Max Weber e de sua obra sejam um dos exemplos mais significativos do caráter bifronte da ciência: tanto como mecanismo de esclarecimento do mundo como quanto mecanismo de encobrimento das relações de poder que permitem a reprodução de privilégios injustos de toda a espécie. É um atestado da singular posição que Weber ocupa no horizonte das ciências sociais perceber que, precisamente por ter captado a "ambiguidade constitutiva" do racionalismo singular ao ocidente (SCHLUCHTER, 1979), ele tenha formulado os dois diagnósticos da época mais importantes para a auto-compreensão do ocidente até nossos dias: uma concepção liberal, afirmativa e triunfalista do racionalismo ocidental; e uma concepção crítica extremamente influente deste mesmo racionalismo, que procura mostrar sua unidimensionalidade e superficialidade.

Para a versão liberal e afirmativa, Weber fornece, por um lado, sua análise da "revolução simbólica" do protestantismo ascético, para ele a efetiva revolução moderna, na medida em que transformou a "consciência" dos indivíduos, e a partir daí a realidade externa, e não o contrário, como na revolução francesa, que termina em restauração do poder monárquico. É a figura do 
protestante ascético, que com vontade férrea e com as armas da disciplina e do autocontrole, quem cria o fundamento histórico para a noção do "sujeito moderno" e até mesmo para a noção moderna de "personalidade" enquanto entidade percebida como um todo unitário com fins e motivos conscientes e refletidos.

A grande maioria das versões apologéticas do "sujeito liberal" nutre-se, quase sempre com fundamento empírico na história da pujança econômica e política norte-americana, em maior ou menor grau, na figura do pioneiro protestante weberiano. Além disso, por ouro lado, é Weber quem reconstrói sistematicamente a lógica de funcionamento tanto do mercado competitivo capitalista quanto do Estado racional centralizado, de modo a percebê-los como instituições cuja eficiência e "racionalidade" não teriam igual. Ainda que a perspectiva liberal apologética se restrinja ao elogio do mercado, confluem, aqui, os aspectos subjetivos e objetivos (institucionais) que fundamentam, de modo convincente, a afirmação do "dado", ou seja, do mundo como ele é.

Mas Weber, e nisso reside sua influência e atualidade extraordinárias, também percebia, no entanto, o lado sombrio do racionalismo ocidental. Se o pioneiro protestante ainda possuía perspectivas éticas na sua conduta, seu "filho" e, muito especialmente, seu "neto", habitante do mundo secularizado, é percebido por Weber de modo bastante diferente. Para descrevêlo Weber lança mão de dois "tipos ideais", ou seja, de modelos abstratos, no caso, de modelos abstratos de condução de vida individual, os quais se encontram sempre misturados em proporções diversas na realidade empírica concreta. Esses "tipos ideais" que explicam o indivíduo típico moderno para Weber são, por um lado, o "especialista sem espírito", que tudo sabe acerca do seu pequeno mundo de atividade e nada sabe (nem quer saber) acerca de contextos mais amplos que determinam seu pequeno mundo, e, por outro lado, o "homem do prazer sem coração", que tende a amesquinhar seu mundo sentimental e emotivo à busca de prazeres momentâneos e imediatos ${ }^{1}$ (ver SOUZA, 1997).

${ }^{1}$ Ver, Souza (1997). 
Se a primeira leitura fornece o estofo para a apologia liberal do mercado e do sujeito percebido como independente da sociedade e de valores supra-individuais, a segunda leitura marcou profundamente toda a reflexão crítica até nossos dias. A percepção do indivíduo moderno como suporte das ilusões da independência absoluta e da própria perfeição narcísica, quando, na verdade, realiza, sem saber, todas as virtualidades de uma razão instrumental que termina em consumismo e conformismo político, está na base de grande parte das vertentes mais influentes do assim chamado "marxismo ocidental". O "marxismo ocidental", denominação ampla que se refere às perspectivas intelectuais que procuraram unir o impulso crítico do marxismo com a analise weberiana do racionalismo ocidental enquanto razão instrumental, foi uma das inspirações fundamentais de praticamente todas as grandes concepções críticas do século $X X^{2}$.

Neste texto nosso interesse é examinar de perto o elemento apologético e o uso do prestígio científico weberiano para a afirmação de uma visão distorcida, conformista e superficial da realidade. Minha tese, que pretendo defender nas próximas linhas, é a de que a própria construção de uma oposição substancial entre sociedades avançadas do centro - Europa ocidental e EUA - e sociedades atrasadas da periferia - por exemplo, as sociedades latino-americanas - foi construído, pelo menos em sua versão mais "moderna" e "culturalista", em grande medida com base nas categorias weberianas.

Nesse sentido, as categorias científicas são utilizadas "por debaixo do pano", ou seja, sem que seu real caráter fique efetivamente explícito, como justificação de uma violência simbólica que, ao fim e ao cabo, funcionam como uma espécie de "equivalente funcional" do racismo. Estou consciente aqui que a certos espíritos mais delicados a aproximação entre "racismo"

\footnotetext{
${ }^{2}$ De Georgy Lukacs até a escola de Frankfurt, passando por Jürgen Habermas e Pierre Bourdieu é difícil se pensar em um grande expoente da teoria social crítica não influenciado por Max Weber. Ver acerca dessa influência Habermas (1986).
} 
e "ciência" provoca um certo desagrado. Talvez o desagrado seja, como muitas vezes, precisamente o "sintoma" de um problema real. Afinal, para o mesmo Weber que estamos discutindo os ricos e felizes não querem apenas ser ricos e felizes. Eles querem ter o direito de ser ricos e felizes. O ponto que mais marca, para mim, a leitura de Weber como pensador crítico é precisamente sua atenção aos processos que "legitimam" o poder social fático e o tornam "sagrado", no contexto das grandes religiões analisadas por Weber, e o tornam "científico" no mundo desencantado de hoje.

Assim, do mesmo modo como o "racismo científico", que possuía projeção internacional até a década de 20 do século passado, partia da superioridade "racial" dos povos brancos e de olhos azuis, a versão "culturalista" do racismo, mais sofisticada, mas, o que é o ponto fundamental, produzida para colher o mesmo efeito, parte da superioridade de "certo estoque cultural" das sociedades do "atlântico norte" como fundamento mesmo da admitida "diferença e superioridade essencial" dessas sociedades. Do mesmo modo que no racismo de fundo "racial" é construída uma separação "ontológica" entre sociedades "qualitativamente distintas" onde as diferenças não são de "grau", ou seja, não são quantitativas, mas de "essência", implicando a noção de "sociedade superior" - assim como de "indivíduos superiores" que a compõem - no sentido moral do termo.

É preciso notar, especialmente para certo tipo de leitor que receia uma "extensão indevidamente polêmica" do conceito de racismo que o "procedimento" - a distorção simplificadora da realidade - e o "efeito" - a construção de uma fronteira entre "gente" e "sub-gente" de modo "ontológico" funcionando como uma "pré-compreensão", uma dimensão não discutida, de grande parte dos conceitos e noções que utilizamos - são precisamente os mesmos do "racismo científico". Minha tese é, portanto, que a obra de Max Weber foi utilizada em sua versão apologética para conferir "prestígio científico" a uma visão de mundo atrelada a interesses particulares que se mascaram com a universidade e a neutralidade apanágio do prestígio científico. Isso fica claro quando o atributo 
de "universal" é atrelado às sociedades centrais, e o atributo de "particular" ou "regional" é reservado às sociedades periféricas. O objetivo deste texto é, nesse sentido, construir a categoria de "racismo culturalista" e demonstrar o caráter de violência simbólica desta visão científica até hoje hegemônica tanto no centro quanto na periferia.

Pretendo defender essa tese em dois passos: 1) reconstruindo o debate central e periférico que usam essas categorias como seu eixo central; e 2) demonstrando o potencial de distorção sistemática da realidade social das teorias até hoje hegemônicas no discurso científico internacional.

\section{O teatro de espelhos da oposição entre confiança/racionalidade e corrupção/afeto}

O racismo velado do "culturalismo científico" opõe e separa como configurações qualitativa e substancialmente diferentes as sociedades ditas "avançadas" e as ditas "atrasadas" ou como manda o politicamente correto, as "sociedades em desenvolvimento". Essa oposição é construída simultaneamente na dimensão cognitiva e moral, ou seja, as sociedades avançadas e por extensão seus membros são percebidos como mais "racionais", ou seja, o dado cognitivo, assim como "moralmente superiores", ou seja, o dado moral. Como essas categorias só são compreensíveis na relação especular e dual com suas oposições binárias, as sociedades atrasadas, as sociedades latino-americanas no nosso caso, têm então que serem construídas como negatividade tanto na esfera cognitiva como na esfera moral. E é precisamente o que acontece na realidade. Assim, para fazer a oposição especular perfeita, as sociedades latino-americanas são percebidas por todas as versões hegemônicas deste culturalismo como "afetivas e passionais" e tendencialmente corruptas. 
Como o afeto é percebido na hierarquia moral ocidental como o "outro" da razão deste Platão ${ }^{3}$ - e como a doutrina platônica da virtude foi transformada no caminho da salvação cristã, essa doutrina tornou-se a base cotidiana e inconsciente de toda ética ocidental - ele induz diretamente à ideia de uma "reflexão não distanciada" de afetos primitivos, ou seja, cognitivamente inferior. Em grande parte, como resultante da própria tese da dominação dos afetos temos, também, a ideia de uma suposta orientação "particularista" - a famosa preferência "pessoal" ao invés do domínio da impessoalidade - do comportamento das sociedades latino-americanas que as tornariam essencialmente corruptas. A corrupção ou a desconfiança generalizada também seria, é claro, um apanágio dos habitantes dessas mesmas sociedades.

Como essa oposição é criada e legitimada "cientificamente" e o que isso tem ver com a obra weberiana? Max Weber oferece os conceitos centrais por meio dos quais foram pensados e tornados vida prática essa divisão racista entre "gente" superior, das sociedades avançadas, e "sub-gente" inferior, das sociedades latino-americanas e periféricas. Mais que isso. Max Weber é uma espécie de "chave mestra" que nos permite abrir o registro profundo desse "racismo científico" amplamente dominante em todo lugar, ainda que até hoje inarticulado, mas, por isso mesmo, "naturalizado" e aceito por todos seja na esfera científica seja na esfera prática e cotidiana de todas as sociedades modernas 4 .

$\mathrm{Na}$ impossibilidade de tratar de todos os elementos que explicam essa conexão irei escolher os mais representativos e importantes de modo a tornar convincente e plausível meu argumento. Tomemos então três obras representativas que reproduzem com fidelidade o que acabamos de dizer: as obras

\footnotetext{
${ }^{3} \mathrm{O}$ argumento que liga a herança platônica à hierarquia moral do ocidente talvez tenha sido melhor desenvolvido em todas as suas consequências por Charles Taylor do que qualquer outro pensador. Ver Taylor (1989).

4 Jürgen Habermas utilizou procedimento semelhante no seu "Der philosophische Diskurs der Moderne", Suhrkamp (2005) ao utilizar Nietzsche como "chave mestra" (Drescheibe) do pensamento pós -moderno.
} 
de Talcott Parsons - o mais importante sociólogo americano do século XX - nos Estados Unidos e as obras de Gilberto Freyre e Sérgio Buarque - os fundadores da moderna sociologia brasileira - no Brasil. Weber tanto foi utilizado por Talcott Parsons, a partir dos anos 30, para criar uma imagem idealizada da sociedade americana, especialmente - ainda que não apenas - na construção de seus "pattern variables" que se tornou o eixo teórico central de toda a "teoria da modernização", influente ainda hoje, ainda que outras roupagens; quanto, também, foi utilizado por teóricos latino americanos, também a partir dos anos 30, para a construção de uma interpretação "orientalizada" da América Latina ${ }^{5}$. O conceito central dessa versão hoje ainda dominante foi e é o conceito de "patrimonialismo", retirado de modo a-histórico e sem rigor analítico da obra weberiana como iremos ver em maior detalhe a seguir.

Ambas as construções são como imagens no espelho de uma e outra. À construção do predomínio do "primitivo", "pessoal" e "corrupto", como marcas da sociedade patrimonialista, temos a afirmação da "modernidade", "impessoalidade" e "confiança" típicas das sociedades centrais. Esse quadro vigora até hoje nas "ciências da ordem" hegemônicas praticamente sem críticas. Esse ponto para mim é fundamental posto que permite demonstrar que a partir de um fundamento comum; uma leitura unilateral da tese weberiana da especificidade do ocidente, pôde se constituir uma leitura hegemônica das ciências sociais contemporâneas cujo núcleo é um "equivalente funcional" do racismo científico antes dominante. $\mathrm{O}$ que antes era legitimado como diferença racial e biológica passa a ser obtido pela noção de "estoque cultural", num caso, o das sociedades do atlântico Norte, cognitiva e moralmente superior, e no caso exemplar das sociedades latinoamericanas, cognitiva e moralmente inferior. É importante sempre notar que não são apenas as sociedades que são "inferiores" nos dois aspectos decisivos da moralidade dominante; o cognitivo e o moral. Também os "habitantes" dessas sociedades passam

\footnotetext{
${ }^{5}$ Uso aqui uma adaptação livre do termo cunhado por Edward Said.
} 
a ser vistos como indignos de confiança, basta ver a representação dos mexicanos na imensa maioria dos "westerns" americanos, e potencialmente corruptos.

Mas isso ainda não é o mais importante. Hoje em dia partese do pressuposto que a "teoria da modernização" morreu no final da década de 60 (KNÖBL, 2002) quando alguns de seus próprios arautos mais importantes passaram a criticar de forma decidida alguns dos pressupostos centrais dessa teoria. Isso simplesmente não é verdade. Os pressupostos do "racismo cultural" da teoria da modernização continuam a operar até hoje em literalmente todas as grandes teorias sociais que pretendem lidar com a sociedade mundial. Algumas indicações acerca disso serão feitas na segunda parte deste texto.

Como se inicia o "racismo culturalista", até hoje dominante, e como ele se desdobra em uma versão central e outra periférica? $\mathrm{O}$ culturalismo que passa a ser a leitura dominante nas ciências sociais americanas com a crítica ao "racismo científico" em boa parte devido ao prestígio da obra de Franz Boas (STOCKING, 1996) na primeira metade do século XX, não começa com Parsons. Mas Parsons constrói a síntese mais coerente do ponto de vista teórico e mais influente do ponto de vista pragmático/político.

A questão básica da sociologia para Parsons é perceber como a ação social pode ser integrada por meio de valores compartilhados socialmente. Nesse sentido, a questão de perceber como os valores orientam a ação é o objetivo maior da ciência social. A construção das pattern variables levada a cabo por Parsons e Edward Shills em "Toward a general theory of action" (PARSONS et al., 1965) espelhava precisamente pares dicotômicos de orientações valorativas que permitiriam determinar o sentido da ação social em qualquer contexto. Os pólos dessas variáveis espelhavam precisamente a oposição entre racional, impessoal e universal, de um lado, e afetivo, personalista e particularista, por outro lado.

A importância deste esquema para as ciências sociais americanas e depois para toda a ciência social do pós-guerra foi retumbante. Não existia praticamente nenhuma área das ciências 
$\mid 40$ |

Max Weber e o 'Racismo Científico...

sociais que não fosse dominada pela procura da demonstração empírica da validade teórica universal dessas categorias (LATHAM, 2000; GILMAN, 2007). No começo o aspecto mais importante era legitimar científica e politicamente - com farto financiamento das agências estatais americanas nos EUA e fora dele - a superioridade americana em relação a todas as outras sociedades ${ }^{6}$, muito especialmente as do terceiro mundo, de modo a transformar a sociedade americana do pós-guerra em modelo absoluto, concreto e realizado de todas as promessas da modernidade ocidental. A oposição moderno/tradicional utilizada por Weber para explicar a singularidade do ocidente e o "aparecimento do capitalismo apenas no ocidente", no contexto de seus estudos sobre as grandes religiões mundiais, foi utilizado para o estudo dos "entraves para o desenvolvimento do capitalismo em escala global".

Toda a ambiguidade de Max Weber em relação tanto ao capitalismo - produtor de seres humanos amesquinhados precisamente nas dimensões cognitiva e moral (os especialistas sem espírito e homens do prazer sem coração) - e em relação à própria sociedade americana - seu texto nunca comentado pelos culturalistas sobre a hipocrisia como marca indelével da "confiança" interpessoal utilitária do protestantismo americano (WEBER, 2011) - foi cuidadosamente retirada para o uso pragmático e apologético das categorias weberianas para a percepção da sociedade concreta americana do pós-guerra como exemplo acabado de perfeição. Toda a hierarquia mundial tinha o exemplo concreto americano como modelo máximo e todas as outras sociedades eram percebidas como versões mais ou menos imperfeitas desse modelo.

Os efeitos "políticos" desse modelo tornado hegemônico de pensar o mundo são fáceis de serem identificados. Primeiro o efeito conservador e de acomodação para dentro, dado que se os EUA já são perfeitos exemplos de modernidade realizada então não existe nenhuma mudança desejável para a própria sociedade americana. Segundo, como a modernidade é percebida como um conjunto unitário e homogêneo de orientações valorativas todas

\footnotetext{
${ }^{6}$ Por exemplo, os livros clássicos de Banfield (1967) e Almond (1989).
} 
elas apenas positivas, então a legitimação científica da dominação fática dos EUA se torna completa. Novamente, porque a repetição na ciência pode ter a mesma importância que tem na música: esse esquema interpretativo geral não é apenas americano e muito menos limitado ao período do pós-guerra como é sempre muito repetido. Ao contrário, depois da recuperação europeia a partir dos anos 60 e 70 esse esquema continua a ser utilizado apesar das críticas às suas categorias principais com a única diferença que se utiliza agora a palavra "ocidente" como algo restrito às sociedades do "atlântico norte", ou seja, Europa ocidental e EUA/Canadá. É nesse sentido que - o que sempre surpreende alguns latinoamericanos - nesses lugares se fala da América latina como não só não fazendo parte do ocidente, mas, também, como exemplo, aliás, do "outro orientalizado" do ocidente.

Mas que a ciência hegemônica e não crítica nas sociedades afluentes legitime seu próprio poder fático não é muito de se espantar. Afinal a ciência crítica é minoritária em todo lugar. O que causa mais espanto, no entanto, é o fato de que precisamente o mesmo esquema interpretativo foi utilizado também pelas sociedades periféricas - como as latino-americanas - para explicar suas próprias sociedades. Este o fato mais intrigante e o nosso desafio a seguir.

Apesar de Parsons e a teoria da modernização ter exercido e - sempre vale a pena repetir, ainda exercer até hoje - impacto avassalador nas ciências sociais brasileira e latino americana, a gênese do culturalismo brasileiro é operada de modo independente de sua obra. Isso tem a ver com o fato de que os verdadeiros "estratos suporte" - de modo semelhante ao que Weber se referia aos estratos suportes da mensagem religiosa - do liberalismo como interpretação e legitimação da realidade são as classes dominantes de cada sociedade na luta por definir sua própria interpretação particular do mundo como se universal fosse. É apenas a partir dos anos 60 que passa a existir um amálgama entre a interpretação 
autóctone no Brasil com a influência parsoniana, especialmente na ciência política, mas, de modo algum restrito a ela ${ }^{7}$.

A interpretação culturalista brasileira foi criada e imediatamente se tornou hegemônica na década de 30 do século passado com a publicação de Casa Grande e Senzala por Gilberto Freyre. Essa auto-interpretação realiza, pelo próprio punho dos pensadores periféricos, a mais perfeita relação especular com a definição de modernidade e tradição, este último como apanágio da pré-modernidade, que Parsons e seus colaboradores realizariam mais tarde. Na versão original de Gilberto Freyre inexiste a influência de Max Weber, mas a versão mais poderosa e até hoje francamente hegemônica, se deve a uma reformulação - pretensamente baseada em conceitos weberianos - levada a cabo por Sérgio Buarque a partir da interpretação Freyriana.

Desde a publicação do livro A modernização Seletiva (SOUZA, 2000, 2009) $)^{8}$ defendi a tese de que a interpretação que se tornou dominante durante o século $X X$, da realidade social brasileira certamente generalizável a diversas sociedades latino-americanas ${ }^{9}$-, envolve, na verdade, a articulação das noções de personalismo/ patrimonialismo de modo a justificar uma suposta singularidade cultural e social pré-moderna. Essa "pré-modernidade" é o núcleo, nunca na verdade articulado, de noções hoje correntes como "jeitinho brasileiro"; da visão do Brasil e das sociedades latino-americanas como funcionando a partir de uma hierarquia comandada pelo "capital social de relações pessoais" e; portanto, das relações favor/proteção enquanto fundamento da hierarquia social como um todo; assim como da noção de "patrimonialismo"

\footnotetext{
${ }^{7}$ O IUPERJ, e nele figuras como Simon Schwartsmann ou Wanderley Guilherme dos Santos, no Rio de Janeiro, passa a ser um centro dessa influência.

${ }^{8}$ Para a minha percepção inicial da importância da categoria do patrimonialismo na sociologia brasileira, devo muito aos trabalhos seminares de Werneck Vianna sobre o assunto.

${ }^{9}$ As obras de Octávio Paz no México e de Gino Germani na Argentina demonstram que esses temas não eram apenas brasileiros, mas, também, latino-americanos em sentido amplo.
} 
como fundamento de uma "elite estatal" também pré-moderna. Hoje em dia, a tese da "singularidade cultural" brasileira, pensada de modo absoluto como um povo com características únicas e incomparáveis - para o bem e para o mal - é como uma "segunda pele" para todos os brasileiros intelectuais ou não.

A figura de Gilberto Freyre é central neste tema posto que Freyre fundou, literalmente, a forma dominante como o Brasil contemporâneo percebe-se a si mesmo, não apenas neste "romance da identidade nacional" chamado "casa grande e senzala" (FREYRE, 1990), mas em toda a sua obra. Ainda que os temas recorrentes usados na imagem da "identidade" do brasileiro, como "o encontro de raças", sejam tão velhos quanto a independência do Brasil (MACIEL, 2007) - e conseqüentemente da necessidade prática de fontes alternativas de solidariedade social, além do poder local e pessoal dos donos de terra e gente, para a jovem nação que se constituía - foi apenas quando Freyre inverteu a fórmula "racista científica" que condenava a nação de mestiços a um futuro sombrio, que a "identidade nacional" passou a ser um elemento de extraordinário sucesso tomando coração e mentes de brasileiros de norte a sul. Foi Freyre, afinal, o primeiro a articular a tese do "mestiço is beautiful", permitindo interpretar a miscigenação visível e palpável da sociedade brasileira como uma "virtude cultural" - quando durante todo o século XIX era considerado por todos como nosso principal defeito - e sinal, "empiricamente verificável nas ruas", da suposta tolerância e abertura cultural brasileira. Foi Freyre, portanto, quem construiu o "vínculo afetivo" do brasileiro com uma ideia de Brasil, em alguma medida pelo menos, "positiva", com a qual a nação e os seus indivíduos podiam se identificar e se auto legitimar.

Essa ideia caiu como uma luva nos interesses de arregimentação política do governo industrializante e modernizante de Getúlio Vargas e passou, como política do Estado a ser ensinada nas escolas, e a ser cantada em prosa e verso como fundamento mesmo da "unidade morena" da nação brasileira. Afinal, a miscigenação racial funcionava como "redutor de todas as diferenças", especialmente das de classe social e prestígio, 
além de permitir uma associação "espontânea" com ideias como "calor humano", hospitalidade, sensualidade, cordialidade e todas as qualidades ambiguamente "pré-modernas" que hoje são patrimônio afetivo de todo brasileiro. Essa ideia é hoje, portanto, "evidencia não tematizada", tornada uma "segunda natureza" e incorporada à identidade individual de todo brasileiro que se imagina, não obstante todos os inegáveis problemas sociais brasileiros, incorporar virtualidades do comportamento humano que só existiriam por essas bandas tropicais.

Mais ainda. Como a identidade nacional necessita não apenas superar seus inimigos internos - como as solidariedades de sangue e de local - mas também seus inimigos "externos", Freyre jogou todas as suas cartas contra o fantasma presente, de modo implícito ou explícito, na obra de todo intelectual brasileiro ${ }^{10}$ dos últimos cem anos: os Estados Unidos. Sendo de tamanho territorial e populacional semelhante ao Brasil, com história colonial e escravista semelhante, os EUA foram e continuam sendo o êmulo de todo brasileiro à procura de um modelo. Como a comparação nos termos da civilização moderna, baseada no cálculo instrumental e na disciplina, ou seja, no domínio do corpo pela "alma" e pela "mente", nos era e ainda é absolutamente desvantajosa, a construção Freyriana permitia uma "fantasia compensatória", onde nossa inferioridade seria transformada em virtude pela ambigüidade mesma da civilização ocidental, aproveitada de modo conseqüente e inventivo por Freyre. Afinal, são os valores "dominados" do corpo, como diria Pierre Bourdieu, que celebramos na "brasilidade", como o calor humano, a sensualidade, a cordialidade, etc. Freyre inventa literalmente a "pré-modernidade" como virtude, ainda que ambígua, e permite o nascimento do "orgulho brasileiro". Ao construir e sistematizar a auto-imagem "pré-moderna" do Brasil moderno Freyre confere contornos finais a tese da "singularidade cultural brasileira", pensada nele e em muitos outros como uma "singularidade

\footnotetext{
${ }^{10}$ Assim como, talvez, por referência ao segundo maior país latino americano, na obra de intelectuais mexicanos, como Octávio Paz, por exemplo.
} 
tendencialmente absoluta", como se aqui tivesse se produzido, para o bem e para o mal, uma experiência humana singular da vida social neste planeta.

Não existe nenhum grande problema nesta saga nacional. Isso aconteceu em outros lugares de modo muito semelhante e o "mito nacional" não se reduz ao seu "valor como verdade". Ao contrário, fundamental é seu papel de produtor de solidariedades que permitem sociedades concretas enfrentarem guerras, crises e até guerras civis sem se destruir como nação e até saírem fortificadas desses desastres. A virtude da identidade nacional é, portanto, "pragmática". Ela serve a uma função fundamental como "conto de fadas para adultos" cumprindo um papel semelhante ao das antigas religiões mundiais (ANDERSON, 1991). Problemático mesmo é quando o "mito nacional", como ocorre no caso brasileiro, passa a ser a base da própria concepção pretensamente científica da sociedade como um todo. Nesse caso, o que ocorre inevitavelmente é a colonização do interesse na procura da verdade pelo interesse pragmático e político que anima o mito nacional.

O mais interessante no nosso contexto é examinar o modo como o mito da brasilidade e sua celebração das virtudes ambíguas da pré-modernidade se transformam em "ciência" conservadora com toda a "aparência de ciência crítica". Isso nem Parsons e seus colaboradores lograram com tanto sucesso. Esse ponto é fundamental para compreendermos de que maneira as "ideias" dos intelectuais passa a afetar decisivamente a vida prática de uma sociedade legitimando e reproduzindo um cotidiano, como no caso brasileiro ainda hoje, de desigualdade e humilhação. Afinal, no mundo moderno, é a "ciência", substituindo a função das religiões éticas nas sociedades pré-modernas, que detém a "autoridade legítima" para falar no espaço público sobre qualquer assunto relevante. A esfera política não é exceção. A forma dominante de se perceber a política no Brasil foi produto de intelectuais cujas "ideias" foram associadas, de modo intencional ou não, a "interesses" poderosos. Depois de institucionalizadas, essas ideias ganham vida própria e "esquecem" sua gênese e passam a influenciar a pauta dos jornais e a imaginação dos políticos e homens de ação. 
Se quisermos compreender de que modo percepções arbitrárias do mundo se tornam norma de conduta "legítima", inclusive para aqueles que são oprimidos por ela, precisamos "relembrar" sua gênese.

Se pudemos dizer acima que Freyre é o pai-fundador da concepção dominante como o brasileiro se percebe no senso comum, então Sérgio Buarque é o pai-fundador das ciências sociais brasileiras do século $\mathrm{XX}$, e, consequentemente - e muito mais importante - o autor da forma dominante como a "sociedade brasileira" contemporânea se compreende até hoje com a chancela e a autoridade "científica". Sérgio Buarque fez sua obra-prima "Raízes do Brasil" em 1936,10 ou seja, três anos depois da publicação de Casa-grande $\mathcal{E}$ senzala em 1933. Como todos os brasileiros desse período, Buarque foi influenciado decisivamente por Freyre nas ideias pioneiras que desenvolveu neste livro, que me parece, sem sombra de dúvida, o mais influente do pensamento social brasileiro no século XX na medida em que construiu a "ideia-força" (uma ideia articulada a interesses poderosos que permite mascará-los e justificá-los) mais importante da vida política do Brasil moderno.

Qual é a ideia-força que domina a vida política brasileira contemporânea? Minha tese é a de que essa ideia força é uma espécie muito peculiar de perceber a relação entre mercado, Estado e sociedade, onde o Estado é visto, "a priori", como incompetente e inconfiável e o mercado como local da racionalidade e da virtude. O grande sistematizador dessa ideia foi precisamente Sérgio Buarque de Holanda. Buarque toma de Gilberto Freyre a ideia de que o Brasil produziu uma "civilização singular" e "inverte" o diagnóstico positivo de Freyre, defendendo que essa "civilização", e seu "tipo humano", o "homem cordial", é, na verdade, o nosso maior problema social e político.

$\mathrm{Na}$ realidade, Buarque assume todos os pressupostos meta teóricos e teóricos da tese de uma sociedade pré-moderna e dominada pela emotividade e pessoalidade como formulada por Freyre. O que Buarque acrescenta de (aparentemente) novo é transformar a ênfase no personalismo - a emotividade como um dado psico-social que guia as relações interpessoais - da 
interpretação freyriana em ênfase no aspecto institucional e político, ou seja, supostamente patrimonial. O patrimonialismo é uma espécie de amálgama institucional do personalismo, de resto compartilhando literalmente todos os seus duvidosos pressupostos inseridos para fins pragmáticos na construção do "mito" freyriano. É isso que confere o aparente "charminho crítico" de sua tese. Afinal, o "homem cordial" é emotivo e particularista e tende a dividir o mundo entre "amigos", que merecem todos os privilégios, e "inimigos", que merecem a letra dura da lei. Quem exerce a crítica patrimonialista no Brasil o faz com "ar de denúncia", fazendo pose de "intelectual crítico"11. O interessante no argumento de Buarque é que, apesar do "homem cordial" estar presente em todas as dimensões da vida, sua atenção se concentra apenas na ação do "homem cordial" no Estado (BUARQUE, 2011).

É o Estado dominado pelo homem cordial e particularista que se tornará o conceito mais importante da vida intelectual e política brasileira até hoje: o "patrimonialismo" do Estado e da "elite" corrupta. Nos inúmeros seguidores de Buarque, parte expressiva da intelectualidade brasileira até hoje, essa oposição se torna ainda mais simplista ${ }^{12}$. O Mercado capitalista deixa de ser uma instituição ambivalente - fruto de longo aprendizado histórico, que permite tanto separar o interesse econômico de considerações éticas e com isso produzir riquezas em quantidades inauditas, mas, também, produzir e legitimar desigualdades injustas de todo tipo indefinidamente - para ser apenas o reino da "virtude" por excelência. O Estado, também ambivalente, podendo refletir interesses de todo tipo, sendo ele próprio um campo de lutas intestinas, é "congelado" no lado de uma suposta "elite privilegiada", a qual, como ninguém a define, se refere a todos e a ninguém e pode ser usada em qualquer contexto ao bel prazer do falante (quase sempre, ele próprio, de alguma "elite").

11 Em entrevistas empíricas que realizamos mais de 90\% dos brasileiros tendem a identificar os problemas sociais brasileiros com a corrupção estatal (SOUZA et al., 2000).

${ }^{12}$ Ver, por exemplo, Schwartzmann (1973) e Faoro (1984). 
Mas o "toque de Midas" dessa ideologia, que vai explicar a sua adesão popular, é a associação, efetuada "por baixo do pano" e sem alarde, entre mercado e a sociedade como um todo, nos "convidando" a nos sentirmos tão virtuosos, puros e imaculados como o mercado. A partir daí, como a "recompensa narcísica" é o aspecto decisivo, a associação é tornada "afetiva" e, em grande medida, infensa à crítica racional. É precisamente este aspecto que permite a "adesão popular" de setores que não têm nada a ganhar com a "mercantilização" da sociedade como um todo. Desse modo, os partidos liberais no Brasil que representam interesses de uma elite muito pequena, podem "universalizar" seus interesses particulares ao demonizar a intervenção estatal como sempre ineficiente e corrupta. Foi desse modo que, no governo de Fernando Henrique Cardoso, se logrou privatizar em grande medida a universidade pública brasileira (CÂNDIDO DA SILVEIRA, 2009).

É a partir desse raciocínio que o tema da corrupção política passa a ser um dos temas mais centrais e recorrentes do debate acadêmico e político brasileiro. O que está em jogo, no entanto, não é a melhoria do combate à corrupção por meio do melhor aparelhamento dos órgãos de controle. O que existe é uma dramatização da oposição mercado (virtuoso) e Estado (corrupto) construída como uma suposta evidência da singularidade histórica e cultural brasileira. Como já observado, é apenas o "Estado" que passa a ser percebido como o fundamento material e simbólico do patrimonialismo brasileiro. Ora, se todos somos "cordiais", porque apenas quando estamos no Estado desenvolvemos as conseqüências patológicas dessa nossa "herança maldita"? Porque o mercado, por exemplo, não é percebido do mesmo modo? E, porque, ao contrário, o mercado é inclusive visto como a principal vítima da ação parasitária estatal?

É que de Max Weber, de onde se retira a autoridade científica e a "palavra" no sentido do "nome" - patrimonialismo - e não do "conceito científico", para a legitimação científica dessa noção central para a auto-compreensão dos brasileiros, tem-se muito pouco. No Brasil, a influência do pensamento weberiano também é dominado pela mesma leitura liberal apologética que deu origem 
a teoria da modernização de inspiração parsoniana. É de Weber que se retira a autoridade científica e a "palavra", no sentido do "nome" e não do "conceito científico", para a legitimação científica da noção central, ainda hoje, da sociologia e da ciência política brasileira: a noção de "patrimonialismo", para indicar uma suposta ação parasitária do Estado e de sua "elite" sobre a sociedade. Entre nós, no entanto, esse conceito perde qualquer contextualização histórica, fundamental no seu uso por Max Weber, e passa a designar uma espécie de "mal de origem" da atuação do Estado enquanto tal em qualquer período histórico.

A discussão weberiana acerca da noção de patrimonialismo é complexa e multifacetada. No sentido mais formal o patrimonialismoéuma variação do tipo de dominação "tradicional" (WEBER, 1985). Ao contrário das formas "primárias" de dominação tradicional como a gerontocracia e o patriarcalismo, caracterizadas pela ausência de um quadro administrativo, o patrimonialismo se caracteriza pela presença de um quadro administrativo o que traz para Weber as consequências mais importantes para o exercício da dominação política (WEBER, 1985: 134-137). É que na estrutura triádica a partir da qual Weber pensa a dinâmica interna às esferas sociais (WEBER, 1985: 245-381) ${ }^{13}$, o campo político se articula e se define enquanto tal a partir do peso relativo da relação triádica entre o líder, o quadro administrativo e os dominados. A entrada, portanto, do quadro administrativo em cena inaugura, de certo modo, a política em toda a sua complexidade. Isso porque entra em cena também o tema central da "delegação do poder", já que o exercício do poder sobre grande número de pessoas e sobre extenso território exige o quadro administrativo como intermediário entre a liderança e os liderados.

A existência do quadro administrativo é tão importante para Weber que ele irá definir o tipo mais puro do outro tipo além da dominação tradicional e suas variantes - de dominação

\footnotetext{
${ }^{13}$ Ver também o texto primoroso de Pierre Bourdieu (2011: 79-181) acerca da estrutura triádica do campo religioso verificável em várias esferas importantes como a política por exemplo.
} 
permanente e estável ${ }^{14}$, a dominação racional-legal, precisamente pela existência de um quadro administrativo burocrático (WEBER, 1985: 126) onde a eficiência técnica e a estrita obediência à liderança se aproxima o máximo do caso concreto. Isso se explica pelo fato de que a necessidade da delegação do poder irá criar as diversas constelações possíveis de exercício mais ou menos efetivo do poder sobre os liderados, do exercício do poder mais ou menos controlado pelo líder, do exercício mais ou menos de fato nas mãos de quem tem a delegação do poder, etc. Por conta disso, Weber irá definir também as diversas subdivisões do subtipo de dominação patrimonial precisamente a partir da maior importância relativa do líder ou do quadro administrativo.

Quando atentamos para a contextualização histórica deste contexto em Weber, queremos, acima e antes de tudo, enfatizar o fato de que o patrimonialismo não é compatível com esferas sociais diferenciadas, ou seja, nas palavras de Weber nas "considerações intermediárias" e como ele preferia se referir "esferas de valor" (Wertsphären). As esferas de valor diferenciadas implicam que cada qual possui um princípio valorativo ou critério regulador que lhe é próprio e que serve de padrão para a conduta dos sujeitos nessa esfera. Implica também que todo o conjunto de papéis sociais, expectativas de comportamento, construção organizacional e padrões de institucionalização vão se guiar e ser avaliados precisamente pelo mesmo critério regulador. Toda a sociologia weberiana pode, inclusive, ser compreendida como uma tentativa de explicar de modo genético e causal por que apenas no ocidente moderno logrou-se uma configuração social que não só possibilita, mas, também, estimula a diferenciação entre as diversas esferas sociais e o ganho em eficiência e racionalidade (instrumental) que esta mesma diferenciação implica.

Toda a sua explicação do patrimonialismo em todos os seus casos concretos parte precisamente da impossibilidade da existência de esferas sociais diferenciadas no contexto patrimonial.

\footnotetext{
14 A dominação carismática só existiria como "tipo puro" em situações excepcionais (WEBER, 1985: 141- 142).
} 
Isso não quer dizer que não existam "aspectos políticos" ou "aspectos econômicos" da ação social nesses campos, mas essas ações são situadas e contextualizadas, crescendo, por exemplo, em tempos de guerra, para voltar a inexistir em tempos de paz, não desenvolvendo, portanto, todas as virtualidades de um campo diferenciado. Nesse sentido, o patrimonialismo para Weber representa antes de tudo um simples aumento quantitativo da “economia doméstica" (Hausgemeinschaft) (WEBER, 1985: 671, 676), ainda que existam pressupostos ideais novos como a necessidade de legitimação carismática do líder patrimonial (WEBER, 1985: $662)^{15}$. Mesmo que o aumento quantitativo de novas conexões e funções para o exercício do poder sejam requeridas nessa "grande comunidade doméstica", o que acontece, como nota Thomas Schwinn em sua excelente discussão acerca precisamente do caráter necessariamente indiferenciado das esferas sociais no patrimonialismo (WEBER, 1985: 211-302), é a mera substituição do princípio segmentado-horizontal da comunidade doméstica em favor de uma segmentação verticalizada com caráter hierárquico no patrimonialismo (WEBER, 1985: 217).

O aspecto decisivo aqui é que todos os aspectos da vida estão amalgamados de modo radical especialmente, mas não apenas, os aspectos econômicos e políticos. Mesmo que possa existir empreendimentos de grande vulto econômico no contexto patrimonial, como os assegurados por privilégios de monopólio de comércio e manufatura, os mesmos podem ser retirados de modo mais ou menos arbitrário impedindo cálculo e previsibilidade que são indispensáveis à institucionalização da esfera econômica. Está pressuposto no argumento weberiano que é precisamente a irremediável confusão entre as diversas esferas sociais que garante a apropriação do excedente social nos termos patrimoniais: precisamente como "botim livre para a formação de fortunas" dos setores privilegiados (WEBER, 1985: 646, 642).

${ }^{15}$ Ver também Schwinn (2001: 216). 
Como a interpretação dominante do suposto "patrimonialismo brasileiro"16 enfatiza a variante onde o "estamento"(stand), ou seja, onde o quadro administrativo assume a proeminência e o efetivo exercício do poder - em próprio interesse e em desfavor tanto da liderança quanto dos liderados - então nada mais razoável que ilustremos nossa crítica a essa "apropriação indébita" pela comparação com o caso histórico analisado em detalhe por Weber e por ele considerado o caso mais puro de "patrimonialismo estamental" (WEBER, 1985: 650).

Se prestarmos atenção a análise que Weber desenvolve em seu estudo sobre o confucionismo e taoísmo nas suas relações com o império patrimonial chinês (WEBER, 1991), podemos perceber facilmente o quanto seu conceito de patrimonialismo é contextual e historicamente determinado. Como o patrimonialismo jamais se reduz à esfera da política em estrito senso, já que a "esfera política" em sentido diferenciado e estrito ainda não existe, a dominação social implica uma articulação específica de diversos interesses além dos estritamente políticos. Em primeiro lugar, a confusão entre as diversas esferas sociais, da qual o patrimonialismo retira sua própria condição de possibilidade, exige a existência de uma série de fatores sócio-econômicos "externos" ao que chamaríamos hoje em dia de dominação política em sentido estrito. Alguns desses fatores importantes são: a inexistência de uma economia monetária desenvolvida, a existência de um Direito não formal e uma legitimação em grande medida mágico-religiosa do poder político. Todos esses elementos marcam a sociedade chinesa patrimonial.

$\mathrm{O}$ ponto central em todos esses casos parece-me a impossibilidade de "cálculo racional" que todos esses fatores envolvem e estimulam reciprocamente. A extração do excedente social concentrado no estamento patrimonial dos literatos só pode ser obtido em um contexto onde não apenas existe enorme dificuldade de controle pela autoridade central, mas, também,

\footnotetext{
${ }^{16}$ Os dois grandes nomes da recepção weberiana no Brasil são Sérgio Buarque e Raymundo Faoro.
} 
onde a possibilidade de cálculo da atividade econômica e do produto do trabalho, precisamente pelo pouco desenvolvimento da economia monetária é reduzido ao mínimo. Toda a possibilidade de cálculo entre receita e despesa, planejamento e racionalização da vida dependem da existência dessas pré-condições que, no caso chinês, não estavam dadas. As possibilidades de previsibilidade e de cálculo da ação social são, para Weber, os aspectos mais importantes da condução de vida "racional" em qualquer esfera social posto que, na sua ausência, inexiste a possibilidade do cálculo dos meios adequados a dado fim objetivado. Uma parte importante do potencial revolucionário das cidades ocidentais como fator de desestabilização do patrimonialismo ocidental reside precisamente na influência da economia monetária na e para além dos limites da cidade "livre" (SCHWINN, 2001: 259-277).

Como Weber, ao contrário dos seus epígonos, não defende um "culturalismo", onde a influência da "cultura" se dá de modo independente da eficácia institucional, é necessário, em qualquer caso concreto, que exista uma adequação entre os estímulos institucionais imprescindíveis - sejam eles de natureza econômica, política ou jurídica - e certo tipo de condução de vida prática pelos agentes. $\mathrm{O}$ "tipo de dominação patrimonial" pressupõe, no sentido forte do termo, uma configuração institucional específica como sua própria condição de existência. Não atentar a essas précondições é utilizar o "conceito", como mero "nome", ou seja, uma denominação arbitrária desprovida de qualquer contextualização histórica e de qualquer cuidado conceitual.

Dentre os fatores "internos" à esfera política, temos o fato de que na China o estamento de literatos era o estrato social mais organizado e poderoso ainda que em grande medida ineficaz em relação ao poder local dos clãs e da autoridade paterna familiar. Não só desfrutavam de alto prestígio social como também mantinham comunicação entre si e zelavam cuidadosamente pelo monopólio das condições que garantiam seus privilégios. Além disso, estavam representados por toda a China, sendo efetivamente a única instância de poder real. $\mathrm{O}$ "patrimonialismo estamental", como sabemos, é, para Weber, o exemplo mais claro 
de "dominação do quadro administrativo" pela necessidade de delegação do poder, que a expansão dos grandes impérios com grande extensão territorial cria, vinculada simultaneamente à carência dos instrumentos de controle deste mesmo poder fático pelo dominador ou líder. No caso brasileiro, só em meados do século $X X$ se constitui uma verdadeira burocracia com os meios para a atuação em todo território nacional. Mas aqui já num contexto de desenvolvimento capitalista intenso e rápido.

O caso brasileiro era, portanto, muito diferente sob todos os aspectos do caso chinês. Primeiro, tomando como exemplo o caso brasileiro como ilustração, jamais existiu no período colonial qualquer coisa semelhante ao estamento burocrático chinês. A colonização do país foi deixada nas mãos de particulares que eram verdadeiros soberanos nas suas terras onde o Estado português apenas de modo muito tênue conseguia impor sua vontade. Em outras palavras a associação com o feudalismo - que seria também imprecisa - teria mais relação com a realidade do que a ficção patrimonialista. Precisamente a falta de qualquer estrutura de controle e de administração levou a uma forma extremamente descentralizada de desenvolvimento das "capitanias" como eram chamadas então as estruturas descentralizadas. Uma exceção histórica foi o ataque fiscal aos lucros das minas na província de Minas Gerais na segunda metade do século XVII sem que isso tenha levado a constituição de um estamento nacional já que o intuito era meramente fiscal e localizado à região das minas. A partir de 1808 com a abertura dos portos, a economia monetária penetra de modo incipiente no começo, mas com crescente importância e o capitalismo comercial se torna uma realidade interna com cada vez mais importante, implicando a constituição de um sistema bancário e financeiro crescentemente influente nas cidades.

A realidade dos contratos e do Direito formalizado por sua vez, já existia desde a escravidão e convivia com este tendo sempre atraído a atenção de estudiosos do assunto ${ }^{17}$. Nunca houve também, no Brasil ou na América latina, legitimação mágica do

\footnotetext{
${ }^{17}$ Roberto Machado (1995), por exemplo, fez desse tema o seu mote de estudos.
} 
poder político no sentido chinês do termo onde o imperador era a garantia de harmonia no mundo natural e social percebidos como indistintos(WEBER, 1991: 54-79). O caso chinês é típico posto que mostra todas as virtualidades do patrimonialismo como um tipo de dominação e por extensão, quando acompanhando da indistinção de esferas sociais como vimos acima, como um tipo específico de sociedade e de sociabilidade. Toda vez, dado um contexto "tradicional" nos termos weberianos, em que o feudalismo e o poderes locais e descentralizados logram se desenvolver para a forma imperial e centralizada sem os mecanismos modernos de controle do poder burocrático, sem a racionalização da conduta cotidiana, e sem a possibilidade de cálculo econômico racional, o patrimonialismo e seus subtipos tende a se desenvolver como realidade efetiva.

Além disso, entre 1930 e 1980 o Brasil foi o país de maior crescimento econômico no mundo logrando construir um parque industrial significativo sem paralelo na América Latina. Como se pode exibir tamanho dinamismo econômico em um contexto, como o do patrimonialismo, que pressuporia "indiferenciação da esfera econômica" e, portanto, ausência de pressupostos indispensáveis e ausência de estímulos duradouros de toda espécie à atividade econômica? Essa questão por si só seria um desafio intransponível para os defensores do "patrimonialismo brasileiro". Mas ela nunca é feita. Daí esta noção funcionar como pressuposto central nunca explicitado. Para seus defensores de hoje ela seria tão óbvia que dispensa explicitação (LAMOUNIER; SOUZA, 2009) ${ }^{18}$.

$\mathrm{Na}$ sociologia brasileira, portanto, o conceito de patrimonialismo perde qualquer contextualização histórica, fundamental no seu uso por Max Weber, e passa a designar uma espécie de "mal de origem" da atuação do Estado enquanto tal em qualquer período histórico. Em Raymundo Faoro (1984), por exemplo, que fez dessa noção seu mote investigativo com extraordinário impacto e influência até hoje - enquanto na maioria

${ }^{18}$ Ver também o "best seller" A Cabeça do brasileiro" de Alberto Carlos de Almeida (2007). 
dos intelectuais brasileiros ela é um pressuposto implícito embora fundamental - a noção de patrimonialismo carece de qualquer precisão histórica e conceitual. Historicamente, na visão de Faoro, existiria patrimonialismo desde o Portugal medieval, onde não havia sequer a noção de "soberania popular" e, portanto, se não havia sequer a ideia da separação entre bem privado (do Rei) e bem público, o Rei e seus prepostos não podiam "roubar" o que já era dele de direito.

Em segundo lugar, no âmbito de suas generalizações sociológicas, o patrimonialismo acaba se transformando, de forma implícita, em um equivalente funcional para a mera intervenção estatal. No decorrer do livro de Faoro, o conceito de patrimonialismo perde crescentemente qualquer vínculo concreto, passando a ser substitutivo da mera noção de intervenção do Estado, seja quando este é furiosamente tributário e dilapidador, por ocasião da exploração das minas no século XVIII, seja quando o mesmo é benignamente interventor, quando D. João cria, no início do século XIX, as pré-condições para o desenvolvimento do comércio e da economia monetária, quadriplicando a receita estatal e introduzindo inúmeras melhorias públicas.

A imprecisão contamina até a noção central de "estamento", uma suposta "elite" incrustada no Estado, que seria o suporte social do patrimonialismo. O tal "estamento" é composto, afinal, por quem? Pelos juízes, pelo presidente, pelos burocratas? O que dizer do empresariado brasileiro, especialmente o paulista, que foi, no caso brasileiro, o principal beneficiário do processo de industrialização brasileiro financiado pelo Estado interventor desde Vargas? Ele também é parte do "estamento" estatal? Deveria ser, pois foi quem econômica e socialmente mais ganhou com o suposto "Estado patrimonial" brasileiro. Como fica, em vista disso, a falsa oposição entre mercado "idealizado" e Estado "corrupto"?

A noção de patrimonialismo "simplifica" e "distorce" a realidade social de diversas maneiras e sempre em um único sentido: aquele que simplifica e "idealiza" o mercado e subjetiviza e "demoniza" o Estado. Para se amesquinhar ainda mais o horizonte reflexivo e retirar qualquer atenção aos consensos 
sociais e inarticulados que constituem a referência última de qualquer ação política, basta personalizar o debate político, de modo conseqüente, ao nível das telenovelas. À personalização, subjetivização e simplificação do Estado na noção de "estamento estatal" todo poderoso, é acrescentada uma teatralização da política como espetáculo bufo: deixamos de ter "interesses e ideias em conflito" e passamos a ter um mundo político dividido entre "honestos" e "corruptos". O tema do patrimonialismo não só oferece a semântica através da qual toda a sociedade compreende a si própria, mas também coloniza a forma peculiar como o próprio debate político se articula no Brasil e na América latina. O tema do patrimonialismo, precisamente por sua aparência de "crítica radical", dramatiza um conflito aparente e falso, aquele entre mercado idealizado e um Estado "corrupto", sob o preço de deixar a sombra todas as contradições sociais de uma sociedade - e nela incluindo tanto seu mercado quanto seu Estado - que naturaliza desigualdades sociais abissais e um cotidiano de carência e exclusão ${ }^{19}$. Essa é a efetiva função social da tese do patrimonialismo no Brasil.

\section{O racismo culturalista hoje}

As páginas anteriores não são mera reconstrução de "história das ciências", referindo-se a épocas passadas as quais, hoje em dia, lançaríamos um olhar cheio de compreensão histórica a quem não tinha nem poderia ter, dado a certo contexto cognitivo que se impunha a todos, o distanciamento que hoje desfrutaríamos. O contrário disso é verdade. A história que acabamos de resumir é, talvez, a maior história de sucesso das ciência sociais modernas. A teoria da modernização, o filho mais dileto da tradição weberiana apologética, não só não morreu na década de 60 como continua

${ }^{19} \mathrm{O}$ meu próprio trabalho recente se concentra na crítica de nossa tradição sociológica dominante e na construção de uma alternativa verdadeiramente crítica. Ver Souza (2003/2006; 2006;2009; 2010). 
hoje, certamente com outras máscaras e roupagens, a dominar a discussão mundial.

Assim como se diz da ética protestante que ela se tornou a primeira religião a se tornar "profecia realizada" no mundo prático ${ }^{20}$, e, ao se tornar realidade prática, "morre" enquanto religião, já que a religião ocidental pressupõe a tensão com a realidade mundana, o mesmo pode se dizer da teoria da modernização. A teoria da modernização, como a realização mais consumada da leitura apologética da interpretação weberiana do ocidente, só "morre" para se transformar no pano de fundo não tematizado de boa parte das grandes teorias sociológicas, com pouquíssimas exceções ${ }^{21}$, que tematizam a sociedade mundial ou a articulação entre sociedades avançadas e sociedades periféricas.

A leitura apologética weberiana tronou-se uma "segunda natureza" para a sociologia dominante e amplamente hegemônica em todo o planeta. Por "sociologia culturalista" eu não penso, portanto, em um ramo dentre outros dentre diversas sociologias, mas o fundo comum das sociologias, centrais e periféricas, que logram ocupar posição de hegemonia. Ela é, inclusive, o pano de fundo não tematizado de sociologias que reivindicam terem ultrapassado o culturalismo tradicional e ter adentrado em uma nova dimensão da reflexão sociológica como a reflexão de Niklas Luhmann por exemplo. Luhmann usa outro "vocabulário" mas a ideia de uma "corrupção estrutural" das sociedades periféricas, como se esta não existisse nas sociedades modernas centrais que são portanto "idealizadas" e vistas como tendencialmente "perfeitas" de um modo muito próximo como a teoria da modernização clássica fazia - continua a estar presente em toda a sua argumentação ${ }^{22}$.

\footnotetext{
${ }^{20}$ Por exemplo, Cohn (2002).

21 Pierre Bourdieu seria, talvez, uma exceção parcial neste contexto. Infelizmente, Bourdieu não lançou as bases de uma sociologia efetivamente mundial.
}

${ }^{22}$ Ver, por exemplo, Luhmann (2008; 1995). 
Isso para não falar em teorias que explicitamente continuam o legado dessa mesma teoria com grande sucesso de público e crítica como Fukuihama ou Ronald Inglehardt ${ }^{23}$. Também no Brasil de hoje os maiores best sellers das ciências sociais são aqueles que "atualizam" essa mesma leitura do mundo que separa os dignos de confiança e incorruptíveis das sociedades centrais dos corruptos e inconfiáveis das sociedades periféricas. No Brasil, as mesmas categorias, no entanto, servem para mostrar como as classes altas e médias são moral e cognitivamente superiores às classes populares ${ }^{24}$, reproduzindo uma oposição realizada em termos nacionais e regionais na sociologia mundial.

Na realidade, como a outra versão "reprimida" e "dominada" dentre as possíveis leituras do legado weberiano mostra, a modernidade ocidental é um todo ambíguo e contraditório, seja no centro seja na periferia do sistema, e que funciona segundo critérios que muito mais as aproximam do que as distanciam. É possível demonstrar que tanto a hierarquia social quanto a legitimação dessa mesma hierarquia são realizados de modo muito semelhante em todas as sociedades modernas, sejam elas centrais ou periféricas ${ }^{25}$. Existe todo um caminho a ser percorrido para a construção de uma sociologia crítica contemporânea que seja capaz de ser fundada em outro terreno que não o do preconceito travestido de evidência científica. Nesse caminho, é o outro Weber, o Weber crítico esquecido pelos culturalistas de ontem e de hoje, precisamente o Weber que dedicou o melhor de seus esforços a tentar perceber os meandros da legitimação de toda forma de dominação social. Talvez, ele percebesse que, hoje em dia, boa parte da legitimação dos interesses que não se podem exercer a luz do dia são legitimados pela própria ciência que deveria denunciá-los.

\footnotetext{
${ }^{23}$ Ver Inglehart (1990; 1997) e Fukuiama (1992).

${ }^{24}$ Um exemplo recente é, Lamounier (2009). Ver também o "best seller" A Cabeça do brasileiro" de Alberto Carlos de Almeida (2007).

${ }^{25}$ Ver Souza (2007; 2009; 2012).
} 


\section{Bibliografia}

ALMEIDA, A. C. A cabeça do brasileiro. Rio de Janeiro: Record, 2007.

ALMOND, G.; VERBA, S. The civic Culture: political attitudes and Democracy in five nations. Newbury Park/London: Sage, 1989.

ANDERSON, B. Imagined Comunities. Londres: Verso books, 1991.

BANFIELD, E. The moral basis of a backward society. New York: The Free Press, 1967.

BOURDIEU, Pierre. Uma interpretação da teoria da religião de Max Weber. In: A economia das trocas simbólicas. São Paulo: Perspectiva, 2011, p. 79-181.

BUARQUE, S. Raízes do Brasil. São Paulo: Companhia das letras, 2001.

CÂNDIDO DA SILVEIRA, M. O neoliberalismo e a educação no Brasil de FHC, Revista Senso Comum, n. 1, 2009.

COHN, G. Crítica e resignação. S/1: Tao, 2002.

EISENSTADT, S. Tradition, Wandel und Modernität. Berlin: Suhrkamp, 1979.

FAORO, R. Os Donos do Poder. São Paulo: Globo, 1984.

FREYRE, G. Casa Grande e Senzala. Rio de Janeiro: Record, 1990.

FUKUIAMA, F. The end of History and the Last man. New York: Free Press, 1992.

GILMAN, N. Mandarins of the future. Baltimore: John Hopkins University Press, 2007.

HABERMAN, J. Die theorie des kommunikativen Handelns, Vol.II. Berlin: Suhrkamp, 1986.

INGLEHART, R. Cultural Shift in advanced Societies. Princeton: Princeton University Press, 1990. 
. Modernization and Postmodernization. Princeton: Princeton University Press, 1997.

LAMOUNIER, Bolivar; SOUZA, Amaury. A classe média brasileira. Rio de Janeiro: Campus, 2009.

LATHAM, M. Modernization as Ideology. Chapel Hill: The University of North Carolina Press, 2000.

LUHMANN, N. Inklusion und Exklusion. In: Soziologische Aufklärung6. Wiesbaden: VS Verlag, 2008.

. Kausalität im Süden. In: Soziale Systeme 1, H. 1, 1995, p. 7-28.

MACHADO, R. Ao vencedor as batatas. São Paulo: Editora 34, 1995.

MACIEL, F. O Brasil nação como ideologia. São Paulo: Annablume, 2007.

KNÖBL, W. Spielräume der Modernisierung. Weilerwist: Velbrück, 2002.

PARSONS, T. et al. Toward a general Theory of action. New York: Harper Torchbooks, 1965.

SCHWINN, Thomas. Differenzierung ohne Gesellschaft: umstellung eines soziologischen Konzepts. Weilerwist: Velbrück, 2001, p. 216.

SCHLUCHTER, W. Die Entwicklung des okzidentalen Rationalismus. Tübingen: J. C. B. Mohr, 1979.

SCHWARTZMAN, S. São Paulo e o Estado nacional. São Paulo: DIFEL, 1975

SOUZA, J. (2003/2006). A construção social da subcidadania. 2ª ed. Belo Horizonte: UFMG, 2012.

. A invisibilidade da desigualdade brasileira. Belo Horizonte: UFMG, 2006. . A modernização seletiva. Brasília: UnB, 2000. 
- A ralé brasileira: quem é e como vivem. Belo Horizonte: UFMG, 2009.

. Batalhadores Brasileiros: nova classe média ou nova classe trabalhadora? Belo Horizonte: UFMG, 2010.

- Die Naturalisierung der Ungleichheit. Wiesbaden: VS Verlag, 2007.

. O Brasil além do mito: quem é e como vive a "ralé" brasileira. Belo Horizonte: UFMG, 2009.

- Patologias da modernidade, um diálogo entre Weber e Habermas. São Paulo: Annablume, 1997.

SOUZA, J. et al. Valores e Política. Brasília: UnB, 2000.

STOCKING, G. Volksgeist as method and ethic: essays on boasian ethnography and the German anthropological tradition. Madison: Wisconsin University Press, 1996.

TAYLOR, C. Sources of the self: the making of the modern identity. Cambridge/London: Harvard University Press, 1989.

WEBER, M. Die protestantische Sexten und der Geist des Kapitalismus. München: C. H. Beck, 2011.

- Die Wirtschaftsethik der Weltreligionen: Konfuzianismus und Taoismus. Tübingen: J. C. B. Mohr, 1991. . Wirtschaft und Gesellschaft. Tübingen: J. C. B. Mohr, 1985, p. 130-139. 